\title{
Development and approbation of the method of microcircuits interchangeability efficiency evaluation in radar equipment based on critical circuit and parametric characteristics set
}

\author{
A.A. Shabanov ${ }^{1}$, M.G. Putrya ${ }^{2}$, \\ National Research University of Electronic Technology, Moscow, \\ ${ }^{1}$ shabanov.andr1@yandex.ru, 2pmg@miee.ru
}

\begin{abstract}
The research of the basic parametric characteristics of integrated circuits that affect the radar equipment was conducted, a comparative analysis of modulators and demodulators was carried out and the methodological approach of assessment of effectiveness of interchangeability of chips in a radar equipment is tested.
\end{abstract}

Keywords - electronic component base, radiolocation, radar equipment, missile and space equipment, microwave microelectronics.

\section{INTRODUCTION}

In the development, improvement, and repair of equipment, it is often necessary to replace electronic components. In particular, such situations are common in radar equipment. Accordingly, an important aspect of substitution is the development of certain techniques and technologies that allow the replacement of electronic components with improvement (or preservation) of the technical characteristics of the equipment. An analysis of the current state of microelectronics research showed no specific technique for evaluating chip interchangeability in radar equipment. The authors of various studies mainly study the issue of import substitution and the importance of this process, however, their research focuses more on the specific use of imported chips in military equipment. For example, in one of the articles, the authors discuss the problems of import substitution of the electronic component base in the defense sphere. Based on the production experience, the authors assess the domestic and imported electronic component base, analyze state measures on import substitution and propose concrete actions in the use of the import base [1]. However, this study does not have a specific methodology for evaluating the efficiency of chip interchangeability, there are no recommendations for improving the characteristics of integrated circuits (IC) under development but only shows the need to use foreign electronic component base (ECB) in conditions of poor quality of domestic chips under development.

To solve this problem, a chip interchangeability efficiency evaluation method was developed for in radar equipment based on a critical set of the circuit and parametric characteristics.

\section{METHOD DESCRIPTION}

The essence of the developed method for evaluating the efficiency of the chip interchangeability is to determine the critical parameters of the chip under investigation (by comparison with the most competitive analog), in terms of operability, reliability and performance of the unit (s) of the equipment where it is used, as well as to assess the impact of the circuit and parametric characteristics of the chip on the characteristics of the radar equipment.

The basic idea of the method for evaluation of chip interchangeability efficiency is presented in the block diagram in Figure 1.

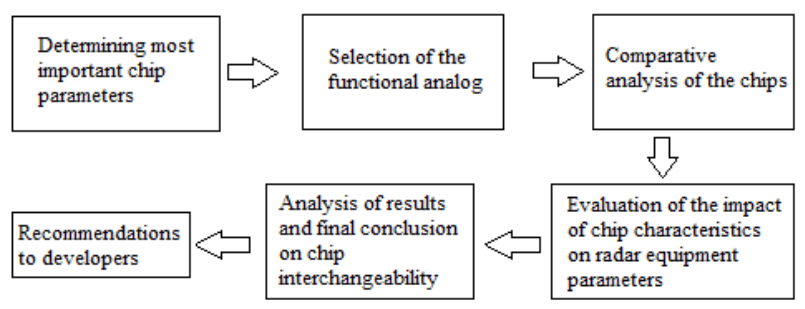

Fig. 1. Block diagram of the method

\section{APPROBATION OF THE METHOD}

The study of the possibility of effective replacement of IC with their improved versions or analogs, the cost of which is considerably lower, was carried out on the example of comparison of modulators and demodulators.

Currently, modulators and demodulators are widely used in radar equipment, especially in transmitters and receivers. The characteristics of the modulators and demodulators directly affect the characteristics of the transmitting and receiving paths, respectively.

For example, increasing the output power, suppressing the carrier frequencies and stray sidebands of the quadrature modulator allow to increase the radiated power of the transmitter, while reducing the consumption current of individual modules provides to decrease the total power consumption, which will permit in the future to introduce new developments with improved technologies into modern radar systems without additional power consumption. 
During the first stage of testing the method, comparative analysis of quadrature modulator 1327MA015 and functional analog of ADL5375 used in radar systems was carried out.

The main comparative characteristics of the 1327MA015 and ADL5375 chips are shown in Table 1 [2, $3]$.

Table 1

The main characteristics of the 1327MA015 and ADL5375 chips

\begin{tabular}{|c|c|c|c|c|c|c|c|}
\hline 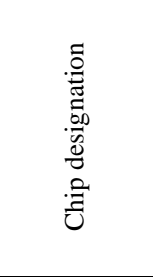 & 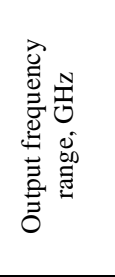 & 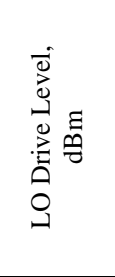 & 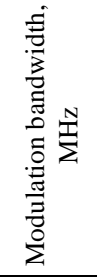 & 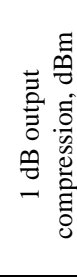 & $\begin{array}{l}\oplus 0 \\
0 \\
0 \\
0 \\
000 \\
0 \\
0 \\
0 \\
0 \\
Z\end{array}$ & 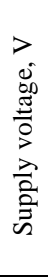 & 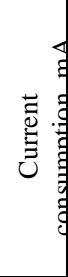 \\
\hline 1327MA015 & $0,7-6,0$ & -7 to +6 & $0-750$ & $+6,5$ & 18 & 5 & 155 \\
\hline ADL5375 & $0,4-6,0$ & -6 to +6 & $0-750$ & +5 & 15,5 & 5 & 195 \\
\hline
\end{tabular}

As a critical set of parameters of the compared ICs according to the developed method, the following set of parameters was determined: consumption current, carrier frequency suppression and sideband suppression, output signal level (power).

One of the most important characteristics of modulators and demodulators is current consumption [4]. In the comparative analysis, the ratio of current consumption to chip temperature was obtained for the 1327MA015 and the ADL5375 (Fig. 2). As a result of the study, at a power supply voltage of $U_{\mathrm{CC}}=5 \mathrm{~V}$ and an ambient temperature of $25^{\circ} \mathrm{C}$, it was found that the consumption current of the chip 1327MA015 is $40 \mathrm{~mA}$ lower than that of the ADL5375, and therefore the power consumption is also lower.

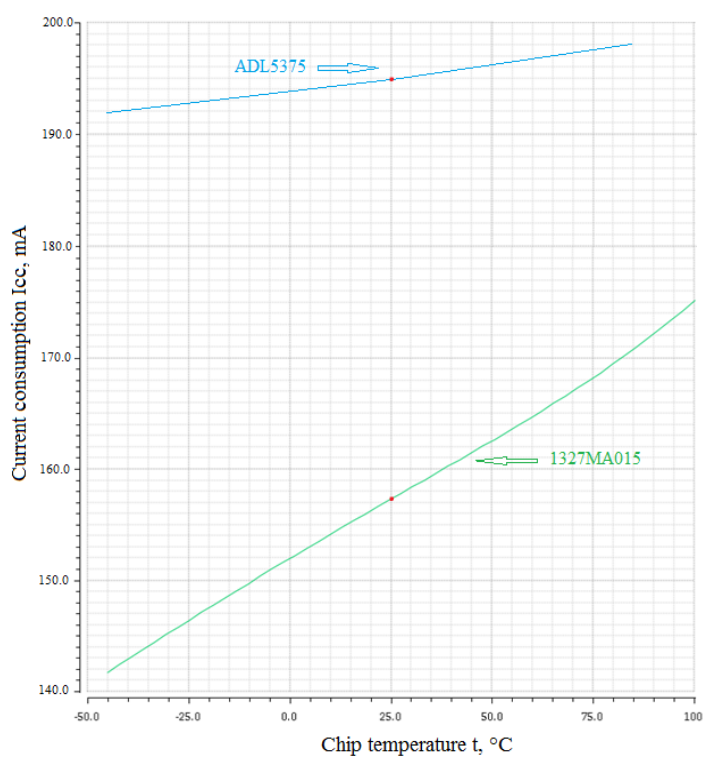

Fig. 2. The ratio of current consumption to chip temperature
Note that the main parameters for modulators are carrier frequency and sideband suppression. In the course of the conducted study, there were obtained ratios of carrier frequency suppression and sideband suppression on local oscillator frequency for 1327MA015 and functional analog of ADL5375 (Fig. 3, 4).

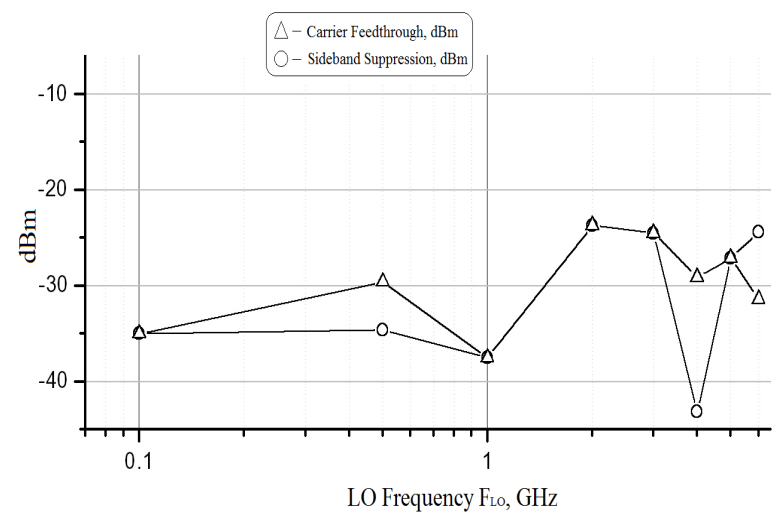

Fig. 3. Carrier frequency suppression and sideband suppression for 1327MA015
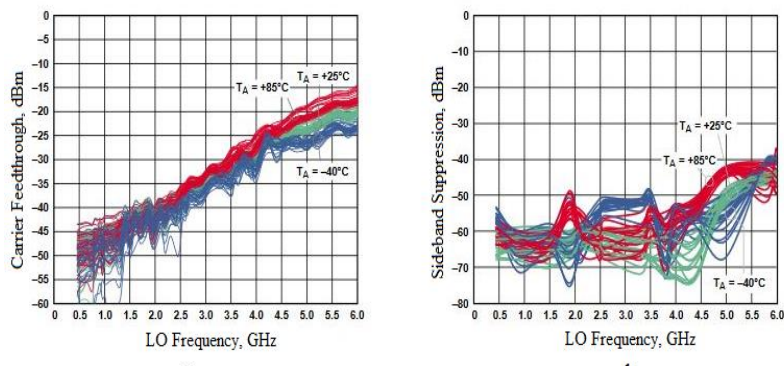

Fig. 4. Carrier frequency suppression (a) and sideband suppression (b) for ADL5375

Analysis of the results of the study showed that the ADL5375 chip is superior to the 1327MA015 chip in suppressing the carrier frequency by $10 \mathrm{dBm}$, and in suppressing the parasitic sideband by $20 \mathrm{dBm}$.

However, in the case of receiving/transmitting paths of radar equipment, this superiority is not critical and is offset by increased power consumption.

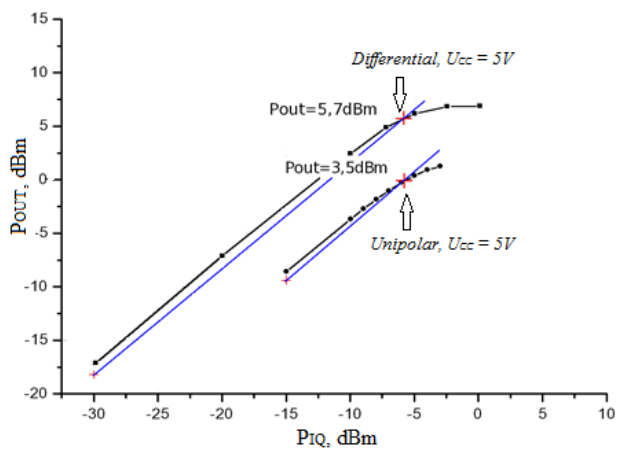

Fig. 5. The ratio of output $1 \mathrm{~dB}$ compression point to the level of the input modulating I- and Q-signals for 1327MA015 
Also, consider the important and necessary parameter for monitoring - output signal level (power). Fig. 5 shows the ratio of the level (power) of the output signal of the modulator (output $1 \mathrm{~dB}$ compression point) $\mathrm{P}_{\text {OUT }}$ to the level of the input modulating I- and Q-signals at the frequency of the modulating signal $\mathrm{f}_{\mathrm{BB}}=10 \mathrm{MHz}$ and at the frequency of the input $F_{I}=3 \mathrm{GHz}$ for $1327 \mathrm{MA} 015$ chip. signal

To perform the comparative analysis, the ratio of the $P_{\text {OUT }}$ output signal level (power) to input frequency $F_{I}$ was obtained at the differential-mode of the ADL5375 chip (Fig. 6).

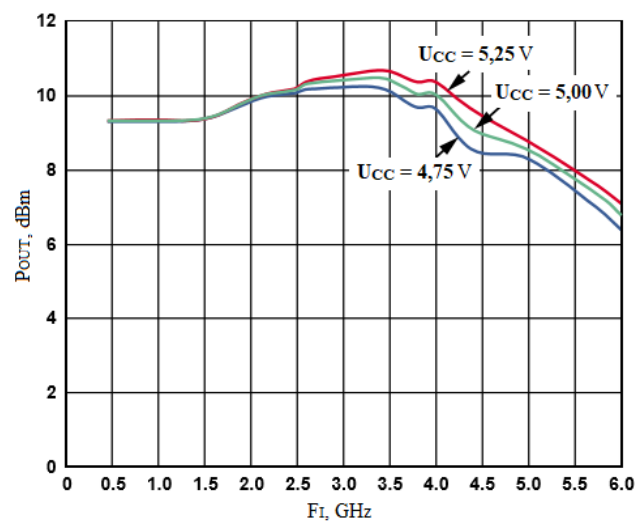

Fig. 6. The ratio of output $1 \mathrm{~dB}$ compression point to input frequency for ADL5375

From graphs 5 and 6 we can see that the output $1 \mathrm{~dB}$ compression point at differential-mode of the ADL5375 chip at the frequency of the input signal $F_{I}=3 \mathrm{GHz}$ is greater than that of the $1327 \mathrm{MA} 015$ chip by $5 \mathrm{dBm}$. However, as the frequency of the input signal increases, the output $1 \mathrm{~dB}$ compression point of the ADL5375 chip drops significantly, and if $F_{I}=6 \mathrm{GHz}$ reaches the values of the $1327 \mathrm{MA} 015$ chip.

Further, a brief parametric comparison of the quadrature demodulator 1327MB015 and the analog ADL5380 shown in Table 2 was performed [2, 3].

Table 2

The main characteristics of the 1327MB015 and ADL5380 chips

\begin{tabular}{|c|c|c|c|c|c|c|c|c|}
\hline 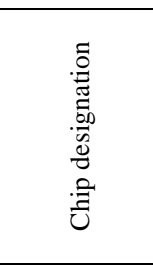 & 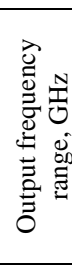 & 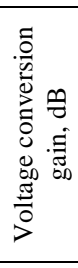 & 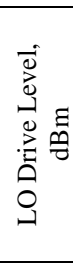 & 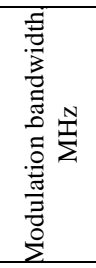 & 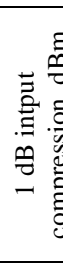 & $\begin{array}{l}\emptyset \\
\theta \\
00 \\
0 \\
000 \\
0 \\
0 \\
0 \\
0\end{array}$ & 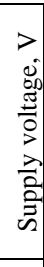 & 离 \\
\hline $1327 \mathrm{MB} 015$ & $\begin{array}{c}0,1- \\
6,0\end{array}$ & 3 & $\begin{array}{c}-7 \text { to } \\
+6\end{array}$ & $0-$ & +6 & 20 & 5 & 155 \\
\hline ADL5380 & $\begin{array}{c}0,4- \\
6,0\end{array}$ & 6 & $\begin{array}{c}-6 \text { to } \\
+6\end{array}$ & $0-390$ & +8 & 15,5 & 5 & 195 \\
\hline
\end{tabular}

As a result of the comparison of the modulators and demodulators, it has been found that the quadrature modulator $1327 \mathrm{MA} 015$ and demodulator $1327 \mathrm{MB} 015$ have an advantage over functional counterparts in power consumption, but worse in noise suppression within acceptable limits. For optimum carrier frequency and stray sideband suppression, subsequent modernization of quadrature modulators requires iterative adjustment between the phase and amplitude of the input signal. The zero value of the stray sideband can be achieved by adjusting the gain for each channel (I- and Q-channels). [5]

However, the main advantage of 1327MA015 and $1327 \mathrm{MB} 015$ chips is domestic production, which will allow enterprises that develop and manufacture radar equipment to qualitatively replace foreign analogs according to the concept of import substitution, but before replacing it is necessary to take into account the criticality of parametric deviations presented above.

By analyzing the obtained data, it may be concluded that the 1327MA015 chip has an advantage over the ADL5375 chip in power consumption, as well as in output signal stability under conditions of increased input signal frequency, but in order to improve the characteristics of the transmitting units of the equipment, it is necessary to improve suppression of the carrier frequency and parasitic sideband.

\section{CONCLUSIONS}

As a result of the study, the main characteristics of quadrature modulators and demodulators were determined, equipment units in which ICs could be used were briefly defined, characteristics of the radar equipment were determined, which could be influenced by chip characteristics, and a method for evaluating the effectiveness of electronic component base interchangeability in radar equipment was tested.

The proposed method will allow to qualitatively improve the technology of evaluation of the interchangeability of ECB in radar equipment. This is achieved by detecting a critical set of IC parameters for each specific case of their application in radar equipment and by detailed analysis of their effect on equipment operability and reliability. The application of this method allows to reduce the number of unclaimed chips developed by domestic enterprises, to improve the quality of the developed ECB, as well as to show clearly which chips and with what parameters it is necessary to develop in order to meet the demand of enterprises producing radar equipment, as well as to obtain additional financial benefit from the production of chips.

Further research and improvement of the proposed methodological approach will make it possible to increase the efficiency of technical solutions for the interchangeability of chips in radar equipment based on a critical set of schematic and parametric characteristics.

\section{ACKNOWLEDGMENTS}

The reported study was funded by RFBR, project number 19-37-90043. 


\section{REFERENCES}

[1] A. E. Alamov, I. Yu Balasov, and V. A. Bazhanov, "Import substitution of electronic components in the production of defense," All-Russian economic journal, vol.11, pp. 17-27, 2015. [in Russian].

[2] URL: https://mri-progress.ru/ (checking date 04.04.2020).

[3] URL: https://www.analog.com/ (checking date 04.04.2020).

[4] R. Shabardin, N. Shabardina, I. Mukhin, D. Morozov and L. Nedashkovskiy. The development of quadrature modulators and demodulators $1800 \mathrm{mhz}-6 \mathrm{ghz}$ with digital correction of parameters. Proceedings of the 2019 IEEE Conference of Russian Young Researchers in Electrical and Electronic Engineering, ElConRus 2019, 2019, pp.1612-1615.

[5] Pun K.-P. Et al. Circuit Design for Wireless Communications. Improved Techniques for Image Rejection in Wideband Quadrature Receivers. Boston, Dordrecht, London: Kluwer Academic Publishers, 2003.

УДК 621.384.5, 537.533

\title{
Разработка и апробация методики оценки эффективности взаимозаменяемости микросхем в радиолокационной аппаратуре на основании критической совокупности схемотехнических и параметрических характеристик
}

\author{
А.А. Шабанов ${ }^{1}$, М.Г. Путряㄴ, \\ Национальный исследовательский университет «МИЭТ», Москва, \\ ${ }^{1}$ shabanov.andr1@yandex.ru, ${ }^{2}$ pmg@miee.ru
}

\begin{abstract}
Аннотация - Данная статья посвящена исследованию, разработке и апробации методики оценки эффективности взаимозаменяемости микросхем в радиолокационной аппаратуре на основании критической совокупности параметрических и схемотехнических и параметрических характеристик модуляторов и демодуляторов отечественных микросхем и их зарубежных аналогов.
\end{abstract}

Ключевые слова - электронная компонентная база, радиолокация, радиоэлектронная аппаратура, ракетнокосмическая техника, СВЧ микроэлектроника.

\section{ЛИТЕРАТУРА}

[1] Импортозамещение электронной компонентной базы в оборонном производстве [Текст] / А. Э. Алямов, И. Ю. Баласов, В. А. Бажанов // ЭКО : всероссийский экономический журнал. - 2015. - N 11. - С. 17-27.
[2] URL: https://mri-progress.ru/ (дата обращения 04.04.2020).

[3] URL: https://www.analog.com/ (дата обращения 04.04.2020).

[4] R. Shabardin, N. Shabardina, I. Mukhin, D. Morozov and L. Nedashkovskiy. The development of quadrature modulators and demodulators $1800 \mathrm{mhz}-6 \mathrm{ghz}$ with digital correction of parameters. Proceedings of the 2019 IEEE Conference of Russian Young Researchers in Electrical and Electronic Engineering, ElConRus 2019, 2019, pp.1612-1615.

[5] Pun K.-P. Et al. Circuit Design for Wireless Communications. Improved Techniques for Image Rejection in Wideband Quadrature Receivers. Boston, Dordrecht, London: Kluwer Academic Publishers, 2003. 